\title{
Gestão da Produção de Recursos Educacionais em Áudio e Vídeo: A Experiência do Laboratório de Educomunicação da Universidade Franciscana/ RS
}

Production Management of Educational Resources in Audio and Video: The Experience of Educommunication

Taize de Andrade Machado Lopes ${ }^{* 1}$, Fabiana da Costa Pereira', luri Lammel Marques ${ }^{1}$

1 Universidade Franciscana. Rua Silva Jardim, 1175 - Santa Maria, RS - Brasil. taize@unifra.br

\section{Resumo}

Este artigo consiste num relato de experiência que teve como objetivo descrever como ocorre o processo de produção de áudios e vídeos didáticos no Laboratório de Educomunicação da Universidade Franciscana, em Santa Maria/RS, além de compartilhar reflexões provenientes das experiências vivenciadas pela equipe multidisciplinar de apoio, composta por profissionais de áreas como Ciência da Computação, Jornalismo, Publicidade e Propaganda e Pedagogia, entre outras, além de equipamentos tecnológicos específicos. A experiência dos autores como gestores da EAD demonstra que é imprescindível a definição de um fluxo de produção e sistema de controle, construção de cenário e padronização do figurino para as videoaulas, roteirização dos conteúdos e capacitações docentes regulares. Como conclusão, ressalta-se que, apesar de os custos institucionais de produção serem significativos, sua disponibilização é imprescindível, na medida em que são instrumentos eficazes em aulas a distância, tornando-as mais atrativas para o estudante e potencializando o ensino-aprendizagem.

Palavras-chave: Educação a distância. Videoaula. Audioaula. Universidade Franciscana. 


\title{
Production Management of Educational Resources in Audio and Video: The Experience of the Educommunication Laboratory of the Franciscana University/ RS
}

\section{Abstract}

This article aims to describe how the production process of audio and didactic videos takes place in the Laboratory of Educommunication of the Franciscana University, in Santa Maria / RS. It shares reflections from the experiences of the multidisciplinary support team, composed by professionals from such areas as Computer Science, Journalism, Advertising and Teacher Preparation, among others, as well as specific technology equipment. The researchers' experience as managers of the Distance Education Program demonstrates that it is essential to define a production flow and control system, scenario set up and costumes standardization for video lectures, content scripting and regular teacher training. The conclusion is that, although the institutional costs of production are significant, their availability is essential since they are effective tools in distance classes, making them more attractive for the student and enhancing teaching and learning.

Keywords: Distance education. Video Lecture. Audio Lecture. Franciscana University.

\section{Introdução}

É significativa a expansão dos cursos superiores a distância na última década no Brasil. Conforme dados do Censo da Educação Superior, em 2006 cursos a distância matricularam 207.206 estudantes, enquanto em 2016 foram 1.494 .418 - um aumento de mais de 700\%. Ou seja, em apenas dez anos houve crescimento de mais de 1,2 milhão de matrículas, enquanto na modalidade presencial esse aumento foi de aproximadamente $40 \%$ no mesmo período (INEP, 2006; 2016). Esses dados demonstram a importância da modalidade Educação a Distância como instrumento de democratização do Ensino Superior no Brasil. Entretanto, implicitamente, levantam preocupações acerca da qualidade do material didático que é disponibilizado aos estudantes, dada a escala com que cursos a distância têm sido ofertados.

Conforme o Decreto n 9.057, de 25 de maio de 2017, novo marco regulatório da Educação a Distância (EaD) no Brasil,

\begin{abstract}
considera-se Educação a Distância a modalidade educacional na qual a mediação didático-pedagógica nos processos de ensino e aprendizagem ocorra com a utilização de meios e tecnologias de informação e comunicação, com pessoal qualificado, com políticas de acesso, com acompanhamento e avaliação compatíveis, entre outros, e desenvolva atividades educativas por estudantes e profissionais da educação que estejam em lugares e tempos diversos (BRASIL, 2017).
\end{abstract}

A definição de $\mathrm{EaD}$, que é considerada uma modalidade educacional para fins do Decreto, demonstra a complexidade institucional envolvida na oferta de cursos superiores a distância. Nos Referenciais de 
Qualidade para Educação Superior a Distância do Ministério da Educação está explícito que, "em consonância com o projeto pedagógico do curso, o material didático deve desenvolver habilidades e competências específicas, recorrendo a um conjunto de mídias compatível com a proposta e com o contexto socioeconômico do público-alvo" (MEC, 2007, p. 13).

Nesse sentido, entende-se que a disponibilização de áudio e vídeo, principalmente em cursos a distância, permite a diversificação dos recursos didáticos produzidos e ofertados ao estudante, tornando as aulas mais atrativas e potencializando a aprendizagem. De acordo com Bahia e Silva (2017, p. 4), a linguagem audiovisual pode proporcionar a aproximação do discente com o "mundo tangível ou figurável", se utilizada consistente e adequadamente, "pois permite que este se perceba implicado no conteúdo abordado, promovendo a reflexão e o pensamento crítico".

Para dar suporte especializado à produção de materiais audiovisuais na EAD da Universidade Franciscana (UFN), foi criado o Laboratório de Educomunicação (Educom), ligado ao Setor de Produção, que conta com equipe constituída de profissionais da área de Comunicação Social Jornalismo, Relações Públicas e Publicidade e Propaganda) e o apoio da TV e rádio da instituição. A gestão da EAD da UFN é organizada em Setor Pedagógico, Setor de Produção, Setor de Tecnologia Educacional e Setor de Tutoria, todos ligados a uma coordenação geral.

Neste relato de experiência, será descrito como ocorre a gravação, a edição e a publicação de materiais didáticos em áudio e vídeo na EAD da Universidade Franciscana. Em razão dos objetivos e da metodologia proposta, a seção 2 aborda brevemente a fundamentação teórica acerca da importância dos recursos audiovisuais na educação e a seção 3 descreve como ocorre a produção desses recursos na UFN. Finalmente, na seção 4 são realizadas algumas reflexões provenientes da experiência dos autores na gestão da produção de conteúdos, especificamente em áudio e vídeo, seguidas das considerações finais e referências.

\section{Produção de Áudio e Vídeo como Recurso Didático na EAD}

De acordo com dados do Censo EaD 2016, da Associação Brasileira de Educação a Distância (ABED, 2017), se forem considerados cursos regulamentados totalmente a distância, 30\% das instituições que responderam ao Censo afirmaram que mais de $75 \%$ dos alunos estudam e trabalham.

Nesse cenário, sabe-se que a EaD é escolhida pelos estudantes por diversos fatores, entre eles a flexibilidade dos momentos de estudo (estudar em qualquer hora e local) e preço dos cursos a distância (que normalmente situam-se abaixo dos preços cobrados na modalidade presencial). Em síntese, essa realidade nacional tão complexa exige das instituições de ensino superior (IES) que ofertam cursos em EaD um cuidado especial com os materiais que serão disponibilizados, levando em conta principalmente esses "trabalhadores que estudam". Recursos em áudio, por exemplo, podem ser ouvidos a caminho do trabalho ou realizando outras atividades. Da mesma forma, a oferta de videoaulas curtas e contextualizadas são atrativas na medida em que podem chamar a atenção do aluno pelos sons e imagens. Ambos, sem dúvida, auxiliam o processo de ensino-aprendizagem tanto de "trabalhadores que estudam" quanto de "estudantes que trabalham".

Para Souza (2016, p. 24), gravações em áudio e vídeo "podem ser usadas para explicar conteúdos ou passagens do texto didático, demonstrar instruções de uso sobre algo, ensinar procedimentos diversos, apresentar opiniões de especialistas, entre outras funções". Moore e Kearsley (2007, p. 82-83) lembram que,

em virtude de sua capacidade para mostrar pessoas interagindo, o vídeo é uma boa mídia para o ensino de aptidões interpessoais e para o ensino de qualquer tipo de procedimento, pois consegue mostrar a sequência de ações envolvidas; pode mostrar closes, movimento lento ou 
acelerado, perspectivas múltiplas e assim por diante. Áudio e vídeo podem ser ambos usados para apresentar as opiniões dos especialistas, o que aumenta a credibilidade e o interesse dos materiais. Áudio e vídeo são especialmente eficazes para a transmissão de aspectos emocionais ou relacionados à atitude de uma disciplina.

Especificamente, Pereira e Magalini (2017, p. 125) entendem que o vídeo “estimula os sentidos, tornando visível a diversidade de elementos que perpassa o imaginário do aluno ao adentrar um determinado conteúdo". Ou seja, um vídeo didático, em qualquer formato, permite ao professor explorar diversos recursos além da fala, na medida em que pode utilizar trechos de filmes, documentários ou diversos outros sons e imagens, atraindo a atenção do estudante durante a exibição do conteúdo.

No entanto, para que tenham qualidade, as gravações em áudio e vídeo requerem planejamento, recursos humanos e técnicos, que possuem alto custo e tempo para produção, não estando ao alcance de muitas IES (SOUZA, 2016).

Bahia e Silva (2017) afirmam que a construção de um vídeo com fins didáticos demanda parceria do docente, que é especialista no assunto, com a equipe de produção de materiais. É nessa perspectiva que o Laboratório de Educomunicação (Educom) foi implantado, com o objetivo de realizar a gestão da produção de material didático em áudio e vídeo. A necessidade de criação do Educom emergiu em 2014, quando houve demanda por gravações de videoaulas para o Curso Superior de Tecnologia em Gestão de Recursos Humanos (CSTGRH), que, naquele momento, estava sendo elaborado para obtenção do credenciamento institucional em EaD.

Verificou-se que seria necessário suporte para os docentes conteudistas, constituindo-se não só da gravação em si, mas também de capacitação técnica desses professores para lidar com a linguagem audiovisual. Dessa forma, ficou sob responsabilidade do Educom a criação do cenário da EAD no estúdio da UFN TV, o formato dos materiais didáticos em áudio e vídeo, além de cursos de capacitação para os docentes.

Observa-se, a partir do contexto descrito, que para a materialização dos produtos didáticos planejados pelos professores conteudistas na Educação a Distância é fundamental a manutenção de uma equipe multidisciplinar de apoio. Os Referenciais de Qualidade para Educação Superior a Distância (MEC, 2007, p. 13-14) já trazem essa preocupação ao afirmar que, para a qualidade do ensino a distância, não bastam as experiências didáticas presenciais. Para a produção dos diferentes materiais se faz imprescindível atender às "diferentes lógicas de concepção, produção, linguagem, estudo e controle de tempo". E completa elencando alguns profissionais necessários à equipe: "profissionais especialistas em desenho instrucional, diagramação, ilustração, desenvolvimento de páginas web, entre outros".

\section{O Processo Produtivo: Capacitações, Roteiros e Gravações de Conteúdo em Áudio e Vídeo na EAD da Universidade Franciscana}

A Universidade Franciscana obteve, em $1^{\circ}$ de março de 2018, o credenciamento institucional para oferta de cursos superiores a distância. No mesmo mês, no dia 23, a IES também foi credenciada como universidade. A instituição localiza-se em Santa Maria/RS, possui 35 cursos de graduação, seis mestrados e dois doutorados, totalizando mais de 5.500 alunos. É uma instituição comunitária, filantrópica, de direito privado e sem fins lucrativos.

A caminhada da Educação a Distância na instituição começou em 2013, em consonância com o Plano de Desenvolvimento Institucional (PDI), a partir da constituição de uma equipe para a gestão do credenciamento para a oferta de cursos superiores em EaD. Entretanto, a partir de 2010, foi criado o Espaço 
Virtual de Aprendizagem Mais Unifra, utilizando a concepção pedagógica interacionista/construtivista (MARQUES et al., 2011). Esse espaço caracteriza-se por ser um repositório de conteúdos digitais e objetos de aprendizagem produzidos pelos docentes da Universidade, fruto do conhecimento adquirido pelos professores da IES, quando da participação no projeto Rede Interativa Virtual de Educação - Rived.

Finalmente, em 2011, foi criada a Unidade de EAD e, a partir de 2013, passou-se a criar e executar o projeto de credenciamento em Educação a Distância, com a constituição de equipe de professores conteudistas, tutores, técnicos administrativos e a criação de curso superior na modalidade EaD para avaliação do Ministério da Educação. Em 2015, as visitas dos avaliadores do MEC tiveram início, sendo finalizadas em março de 2017, com a avaliação do polo de Brasília.

Quando implantado em 2014, umas das primeiras demandas do Educom foi a criação do cenário para gravação das videoaulas e a padronização do figurino utilizado pelos professores conteudistas. Além disso, foi definido que os cursos em EaD poderiam ter diferentes formatos de conteúdo multimídia. Em síntese, as possibilidades de formato de conteúdos em áudio e vídeo na Educação a Distância da UFN podem ser verificadas no quadro a seguir.

Quadro 1: Formatos de conteúdos em áudio e vídeo na EAD da UFN

\begin{tabular}{|l|l|l|}
\hline \multicolumn{1}{|c|}{ Formato } & Local de gravação & \multicolumn{1}{c|}{ Características } \\
\hline $\begin{array}{l}\text { Vídeo de apresentação } \\
\text { do professor }\end{array}$ & UFN TV & $\begin{array}{l}\text { É disponibilizado na apresentação do curso, } \\
\text { para que o estudante conheça o professor e } \\
\text { tenha uma ideia geral dos conteúdos trabalha- } \\
\text { dos e do plano de aprendizagem. }\end{array}$ \\
\hline $\begin{array}{l}\text { Videoaula para exposição } \\
\text { de conteúdos }\end{array}$ & $\begin{array}{l}\text { UFN TV ou outros } \\
\text { ambientes externos }\end{array}$ & $\begin{array}{l}\text { Com até cinco minutos de duração, pode ter } \\
\text { inserção de imagens, slides ou trechos de filmes } \\
\text { e documentários, entre outros, durante a expla- } \\
\text { nação do professor. }\end{array}$ \\
\hline Screencasts & $\begin{array}{l}\text { Rádio UFN e câmera } \\
\text { da UFN TV }\end{array}$ & $\begin{array}{l}\text { Fundamental para mostrar telas de edição, } \\
\text { configurações em softwares ou imagens } \\
\text { relevantes para o cumprimento dos objetivos } \\
\text { da aula. A imagem do professor fica alocada } \\
\text { em um canto da tela. }\end{array}$ \\
\hline Entrevistas e debates & $\begin{array}{l}\text { Rádio UFN } \\
\text { Ambientes externos }\end{array}$ & $\begin{array}{l}\text { Gravadas tanto em áudio (podcasts, por } \\
\text { exemplo) ou vídeo, em estúdio ou ambiente } \\
\text { externo; envolve dois ou mais professores } \\
\text { concomitantemente. }\end{array}$ \\
\hline
\end{tabular}

Fonte: Autores, 2018.

A Figura 1 mostra o resultado final da gravação de uma videoaula para EaD realizada no estúdio da UFN TV. A Figura 2 mostra professores gravando um programa de debate na rádio.

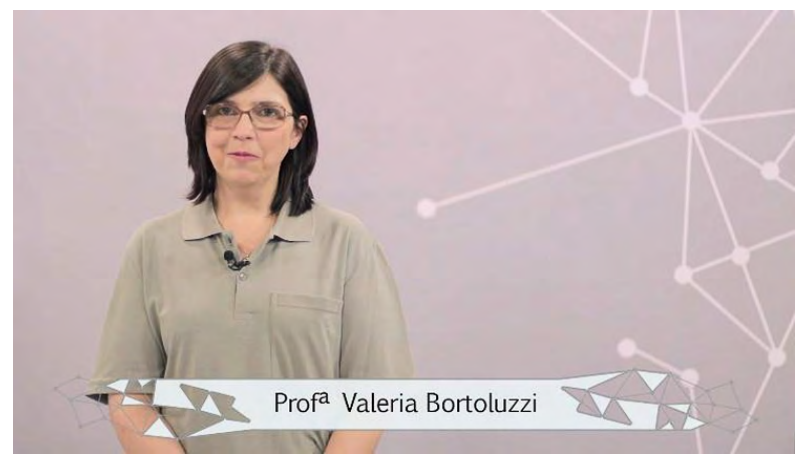

Figura 1: Reprodução de tela de videoaula gravada em estúdio da UFN TV 


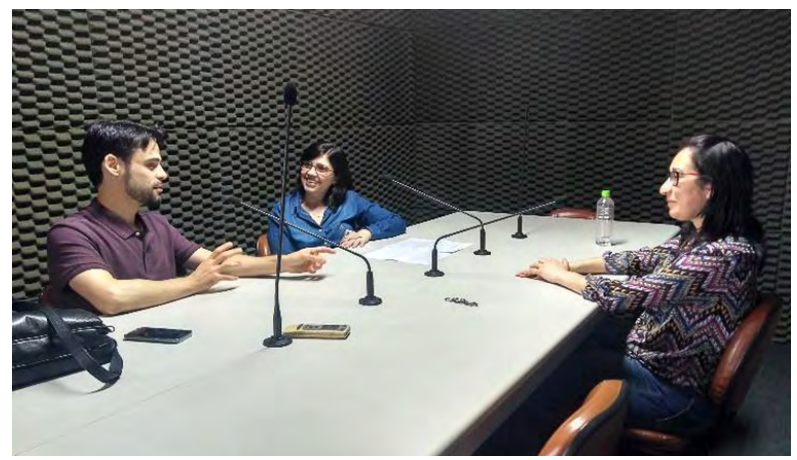

Figura 2: Reprodução de tela de debate gravado como conteúdo em áudio no estúdio da Rádio UFN

Em 2014, foram realizadas capacitações para os docentes do CSTGRH sobre roteirização de conteúdos, técnicas de locução e posicionamento frente às câmeras. Ocorreram outras capacitações específicas para novos grupos nos anos seguintes e, em 2017, foi realizado o curso de extensão Alta Performance para Professores na Educação a Distância. Foram abertas vagas para docentes da modalidade presencial que tivessem interesse em produção de materiais didáticos no formato audiovisual. Os inscritos puderam produzir seus próprios materiais em áudio ou vídeo para serem usados como apoio às aulas presenciais e disponibilizados no ambiente virtual pelo professor.

As atividades do Laboratório de Educomunicação, o Educom, estão diretamente ligadas ao trabalho desenvolvido previamente no Setor Pedagógico, responsável pelo atendimento ao professor conteudista. Este, com o acompanhamento de um orientador pedagógico, estabelece dentro do seu plano de aprendizagem quais conteúdos serão produzidos na modalidade de áudio ou vídeo. O cuidado nesse momento é a orientação ao professor conteudista para que entenda as possibilidades do uso de áudio e vídeo nas aulas, considerando as particularidades do consumo que o público (no caso, alunos) faz desse tipo de material.

Nesse âmbito, é importante solicitar aos docentes que o conteúdo em áudio e vídeo seja planejado de forma adequada, inserindo unidades de aprendizagem relevantes para o cumprimento dos objetivos traçados pelo professor e que possam ser utilizadas em outras edições do curso, dado os custos elevados da produção desse formato de material, como lembrado por Souza (2016).

Definidos os conteúdos a serem trabalhados e o formato que o material terá - usando apenas áudio ou também vídeo -, o próximo passo é a construção do roteiro que guiará a produção. É a confecção do roteiro que exigirá do professor conteudista e do orientador pedagógico a maior dedicação em termos de detalhamento do que será realizado e como deverá ser realizado. Cada informação deverá estar contextualizada quanto à sonorização ou quanto à imagem. Para essa etapa, os professores recebem um modelo de roteiro produzido pelo Educom, baseado nos roteiros televisivos em que as cenas são descritas em uma tabela de duas colunas: uma para a descrição do vídeo (o que aparece na tela) e outra para a descrição do áudio.

É importante compartilhar que pode-se encontrar professores que tenham resistência quanto à produção detalhada do roteiro, mas acabam se convencendo da importância dele ao chegar o dia da gravação. O roteiro finalizado e estudado deixa o professor mais tranquilo e seguro diante das câmeras, evitando que a gravação de uma aula de apenas cinco minutos estenda-se por horas. Bahia e Silva (2017, p. 8) enfatizam que o docente, ao planejar a aula, deve responder questões como “quem é o estudante? Quais aspectos do conteúdo podem sensibilizar e despertar seu interesse? Que relações podem ser estabelecidas entre o conteúdo e a realidade do estudante? De que maneira esse conteúdo pode ter impacto positivo na vida do estudante?". É pensando nessas questões que o docente terá um norte para a escolha do conteúdo, do cenário e da linguagem, entre outros itens. 
Estabelecido o roteiro, a sequência do processo se dá com o agendamento do estúdio de gravação (estúdio de rádio ou de TV), o agendamento do professor e/ou convidado e as orientações para que eles tenham a melhor atuação frente aos microfones e/ou câmeras. Na gravação de material em áudio, é dada atenção especial para a expressividade oral de quem irá gravar, considerando ênfase, pausas e velocidade de fala, entre outros aspectos. No audiovisual, a atenção inicia com os cuidados desde as vestimentas e acessórios, com orientação para o tipo de roupa e as cores que tenham melhor efeito no vídeo, dado que a maioria dos professores não possui experiência frente às câmeras. Também recomenda-se aos docentes que as videoaulas não ultrapassem cinco minutos de duração.

Essa duração é corroborada por Bahia e Silva (2017, p. 4), que afirmam “que a atenção do aluno perdura de modo satisfatório para a aprendizagem no tempo médio de 3 a 5 minutos, podendo, conforme a didática, estender-se até 8 minutos". No caso de conteúdos em áudio, aceita-se uma duração maior, principalmente se forem gravados, como debates ou entrevistas. Entretanto, não é recomendado aos professores que esses materiais excedam os vinte minutos de duração.

O momento de gravação, conforme material a ser confeccionado, não exige, em geral, muito tempo do professor e/ou convidado, considerando que o conteúdo foi previamente repassado e está bem absorvido. Após esse momento, o trabalho fica por conta do produtor do Educom, que irá editar o material que foi gravado em pequenos módulos, montando o produto final a ser disponibilizado para aprovação da equipe pedagógica. Os materiais são posteriormente disponibilizados no ambiente virtual de aprendizagem (AVA), organizados conforme o plano de aprendizagem do professor.

Além das gravações dos professores feitas no estúdio de TV, o editor de vídeo do Educom também recebe materiais gráficos produzidos pelos conteudistas, como imagens e apresentações de slides, a fim de serem utilizados como material de suporte na edição do vídeo. Em alguns casos, os professores fornecem um roteiro para produção desses materiais de apoio acompanhado de imagens retiradas de materiais didáticos ou da Web para servirem de referência. Nesse caso, o desenhista do Setor de Produção recebe esses roteiros e imagens de referência para, então, produzir materiais gráficos originais e autorais que serão utilizados na edição do vídeo. No caso das apresentações de slides, os professores conteudistas recebem previamente um arquivo-modelo, já com a tipografia e o padrão de cores da EAD da UFN, a fim de manter a identidade visual da Unidade em todos os vídeos produzidos pelo Educom.

\section{Reflexões sobre a Gestão da Produção de Áudio e Vídeo a partir das Experiências Vivenciadas no Educom da UFN}

O fluxo da produção dos materiais didáticos para cursos a distância envolve uma gama de processos, o que cria uma rotina preestabelecida e auxilia as equipes envolvidas a executar suas tarefas de forma adequada e nos prazos. Baseado na experiência dos autores com a gestão da produção de conteúdos em áudio e vídeo na UFN, são feitas a seguir breves considerações e reflexões a partir da realidade institucional.

O mapeamento e a publicização dos mapas de gestão ${ }^{1}$ para os atores da EAD são fundamentais. Sugerese que sejam elaborados de forma coletiva, com a participação dos envolvidos nos processos. Além disso, em 2017, a EAD criou um sistema de controle, o Controle de Produção da Educação Virtual (CPEV), para que planos de aprendizagem e roteiros de objetos de aprendizagem ou conteúdos multimídia sejam acompanhados por todos os coordenadores dos setores da EAD. Com o sistema, a coordenação geral pode gerar relatórios e realizar as cobranças necessárias para os setores específicos, caso haja atrasos na produção.

1 Para o credenciamento institucional para a modalidade a distância, a equipe de EAD da UFN elaborou mapas de gestão que descrevem o fluxo necessário, desde a elaboração até a oferta dos cursos a distância 
Na gravação das primeiras videoaulas da UFN, não houve preocupação com o figurino, o que não agradou aos gestores nem aos próprios professores envolvidos, dada a disparidade de cores e tipos de vestimentas no produto final em vídeo. Dessa forma, optou-se pela padronização com camisas-polo, o que resolveu a questão. Também foi importante a construção de um cenário para gravação das videoaulas no estúdio da UFN TV (Figura 1). Finalmente, passou-se a utilizar vinhetas para abertura e fechamento dos vídeos, com a própria logo institucional.

Utiliza-se o modelo de roteiro de duas colunas, com espaço para descrição da fala e imagem relacionadas. Além disso, considera-se importante a IES dispor de orientadores pedagógicos experientes para dar suporte ao professor conteudista na elaboração do roteiro. Entende-se que, para tranquilidade e segurança no momento da gravação, é imprescindível que o próprio professor elabore o roteiro da gravação, tanto para áudio quanto para vídeo. No dia marcado para gravar os conteúdos, o docente deve dominar o roteiro, procurando evitar o teleprompter, que pode tirar a naturalidade do momento de aula.

Os professores normalmente necessitam de capacitações para elaboração de roteiros, técnicas de locução e postura frente às câmeras, entre outros itens, sem prejuízo da formação pedagógica, que também é ofertada pelo Setor Pedagógico. É preciso apoio aos professores que se dispõem a gravar videoaulas, dado o constrangimento inicial frente às câmeras; tem sido verificado que a gravação em áudio sempre é mais cômoda. Com o passar do tempo, os docentes apresentam excelente resultado nas gravações das aulas e incentivam outros colegas a fazer o mesmo.

\section{Considerações Finais}

Atualmente, a Unidade de EAD, por meio do Educom, já produziu mais de 140 materiais, entre audioaulas, videoaulas e screencasts. Eles são utilizados para atividades no ambiente virtual, como apoio às disciplinas presenciais ou como material para os cursos na modalidade Educação a Distância que serão oferecidos pela instituição.

Nesse sentido, o Laboratório de Educomunicação passou a ser uma necessidade, visto que agrega qualidade ao material de áudio e vídeo produzido. O trabalho vai desde as orientações aos professores e convidados no que diz respeito ao uso adequado da voz e da imagem até os cuidados de gravação e edição, para que o produto resultante seja um recurso auxiliador no processo de ensino-aprendizagem.

Ou seja, todo esse processo tem um único objetivo: a produção de conteúdos em áudio e vídeo significativos para o estudante, elaborados com qualidade técnica e que sirvam como instrumento eficaz ao aprendizado dos alunos da modalidade a distância, presencial ou híbrida. O Educom permite a diversificação dos formatos de materiais didáticos e, consequentemente, a possibilidade do uso de metodologias ativas tanto na EaD quanto na modalidade presencial, com o uso de vídeos para a concretização da sala de aula invertida, por exemplo.

Quanto às dificuldades encontradas no processo de produção dos materiais audiovisuais, destaca-se a resistência à produção de roteiros completos por parte dos professores, considerando que exige dedicação antecipada dele na elaboração de suas ideias. Também destaca-se o desconforto desse docente principalmente frente à câmera. Essa situação, ao longo do tempo, foi sendo amenizada com a adaptação e a inserção do professor no contexto da Educação a Distância.

Finalmente, é importante salientar que, apesar de a manutenção de uma equipe multidisciplinar qualificada requerer investimento significativo por parte da IES, a busca pela melhoria da qualidade e entrega desse material em tempo hábil é imprescindível, pois são instrumentos eficazes em aulas a distância, tornando-as mais atrativas para o estudante e potencializando o ensino-aprendizagem. 
Espera-se que este breve relato seja útil para gestores e professores que estejam vivenciando questões parecidas com as que foram relatadas. É importante também enfatizar que o processo de aprimoramento da produção de conteúdos em áudio e vídeo é contínuo, dadas as inovações pedagógicas e tecnológicas, o que leva a equipe da EAD a estar em constante movimento de aprendizagem.

\section{Referências Bibliográficas}

ABED. Associação Brasileira de Educação a Distância. Censo EAD.BR. Relatório analítico da aprendizagem a distância no Brasil 2016. Curitiba: InterSaberes, 2017. Disponível em: http://abed.org.br/censoead2016/Censo EAD 2016_portugues.pdf. Acesso em 07 out. 2018.

BAHIA, Ana Beatriz; SILVA, Andreza Regina Lopes da. Modelo de produção de vídeo didático para EaD. Revista Novas Tecnologias na Educação, v. 15(1), p. 1-10, 2017. Disponível em: https://doi. org/10.22456/1679-1916.75116. Acesso em 12 mar. 2018

BRASIL. Decreto n 9.057, de 25 de maio de 2017. Regulamenta o art. 80 da Lei nº 9.394, de 20 de dezembro de 1996, que estabelece as diretrizes e bases da educação nacional. Disponível em: http://www. planalto.gov.br/ccivil_03/ato2015-2018/2017/decreto/D9057.htm. Acesso em 28 abr. 2018.

INEP. Instituto Nacional de Estudos e Pesquisas Educacionais Anísio Teixeira. Sinopse Estatística da Educação Superior 2006, 2016. Brasília: INEP, 2017. Disponível em: http://portal.inep.gov.br/web/guest/ sinopses-estatisticas-da-educacao-superior. Acesso em 29 abr. 2018.

MARQUES, Iuri Lammel; VASCONCELOS, Janilse Fernandes Nunes; BORTOLUZZI, Valeria lensen. Espaço virtual de aprendizagem Mais Unifra: a rede social como espaço de aprendizagem. In: Congresso Internacional de Educação a Distância (17 Ciaed). Manaus-AM, 2011. Disponível em http://www. abed.org.br/congresso2011/cd/198.pdf. Acesso em 25 abr. 2018.

MEC. Ministério da Educação. Referenciais de qualidade para Educação Superior a distância. Brasília, 2007. Disponível em: http://portal.mec.gov.br/seed/arquivos/pdf/legislacao/refead1.pdf. Acesso em 25 abr. 2018.

MOORE, Michael G.; KEARSLEY, Greg. Educação a distância: uma visão integrada. São Paulo: Cengage, 2007.

PEREIRA, Guilherme de Carvalho; MAGALINI, Lidiane Maria. Videoaulas em primeira pessoa: suas características e sua contribuição para a EaD. Revista EaD em Foco, v. 7(2), 2017. Disponível em: https://doi. org/10.18264/eadf.v7i2.475. Acesso em 28 abr. 2018.

SOUZA, Renato Antonio de. Multimídia no EaD. São Paulo: Cengage, 2016. 